The Social Sciences 14 (12): 423-430, 2019

ISSN: $1818-5800$

(C) Medwell Journals, 2019

\title{
Interplay of Social Forces: A Focus on Regional Innovation Processes
}

\author{
Victor Cepoi \\ Faculty of Information Studies in Novo Mesto, Ljubljasnka cesta 31A, Slovenia
}

\begin{abstract}
In the new local-global interconnection, nation states are losing their influence and legitimacy while economic and cultural transformations are reconfiguring spatial formations. Going in line with the global trends, regions grasp more importance in shaping the political, economic and social environments. As a result, the regional level has an important role in creating a proper socio-economic framework for innovation development which is considered one the engines of development. Relying on the theory of social fields, the research considers three social forces (networks institutions and cognitive frames) as an alternative explanation for innovation processes by encompassing the aspects of different social fields on the regional level. As case studies, there were selected seven regions with different levels of innovation performance. The analysis of the focus groups with regional stakeholders emphasized that these social forces are a special component for explaining innovation processes in the selected case studies.
\end{abstract}

Key words: Regional systems of innovations, social fields, social forces institutions, networks, cognitive frames, qualitative comparative analysis

\section{INTRODUCTION}

In the new local-global interconnection, nation states are losing their influence and legitimacy (Robins, 1999) while economic and cultural transformations are reconfiguring spatial formations. Additionally, the new global complexity and the restructured social order, determined the nation state to lose its supremacy. Going in line with the global trends, regions grasp more importance in shaping the political, economic and social environments. As a result, the regional level has an important role in creating a proper socio-economic framework for innovation development which is considered one the engines of development (Dodescu and Chirila, 2014). The focus is not only on localized learning but also on the intra and inter-regional knowledge flows which reveals the importance of the regional level within the innovation systems. But as any other processes or interactions between agents, between the innovation process and the regional level there should exist a defined mechanism that will make the action happen.

It is considered that innovation processes are confronted with the problem of uncertainty (Beckert, 1999). According to Beckert, not knowing what innovation is brings up the paradox of needing innovation. Therefore, firstly it is necessary to determine the optimal level of investment for R\&D. For example, real GDP growth and innovation levels are positively linked. But without knowing the pay-offs, it is hard to determine the optimal resource allocation. Secondly, the problem arises in understanding the innovation process, due to not knowing the innovation goal (Beckert, 1999). The field of innovation becomes increasingly interested in scholars from various domains. Along with the development of the topic, national innovation systems and regional and sectorial innovation systems have captured the interest of researchers dealing with this topic (Kastelle, 2009).

Because of changing environments, a system cannot survive without adaptive capabilities and dynamic investment. Therefore, the innovation system is considered an important aspect of the operational activity. The innovation system is a macro-economic unit of national economies and it can be either a firm industry or region (Kastelle, 2009). The understanding of innovation structures should not rely on the perception as a static process. The innovation structure is in a constant evolution which induces the creative and destructive processes in the real economy. The research in national innovation systems has led to the development of the regional innovation systems (Cooke, 1992). For each macro unit, there is a particular innovation system. As an example, the national economy has the national innovation system. Following this line of argument, it can be argued that when the focus is on supra-national, regional or sub-regional level there will be supra-national, regional or subregional innovation system, respectively (Kastelle, 2009).

Considering the importance of understanding innovation processes regarded as complex activities, the aim of this study is to provide an explanatory with the help of social field theory that can applied to different contexts regardless of their level of development. However does the interplay of the social forces shape the regional innovation process? To address these challenges, the paper highlights the interaction of the three forces (networks institutions and cognitive frames) in the context 
of regional innovation processes. The study aims to explain the innovation processes in different regions by using fuzzy-set analysis. As a result, we hypothesize that the three social forces (institutions, networks and cognitive frames) constitutes necessary and sufficient conditions to obtain innovation as an outcome.

Social fields theoretical considerations toward the process of innovation in regions: The notion of field is used in several disciplines which means that it could be a guiding concept for interactional community study for sociologists (Wilkinson, 1970). The term of "field" can refer to a configuration formed by the object and its context; to the context of an object; to a structure or to a structure-process and other. At the same time, it will never refer to the object alone. Each field has several features. Firstly, the environment and the individual in the environment constitute an inseparable unity or field. Secondly, the field is not static. It always changes and operates through time. Lastly, the integral feature is novelty, be it a random happening or creativity (Wilkinson, 1970).

Fligstein and McAdam (2012) argue that any particular field is embedded "in a broader environment consisting of countless proximate or distal fields as well as states which are themselves organized as an intricate system of strategic action fields". As a result, the researchers encompass the idea of social skill. It implies the agency of actors and draws on ideas of constructivism and emergence which are crucial components of the strategic action fields.

Sociology explains economic processes with the help of social structures on individual actions. Following this line of argument, hereby we refer to three social forces that are relevant for economic outcomes: social networks institutions and cognitive frames (Beckert, 2010). In addition, it is considered that these forces do not act autonomously but rather interact with each other.

On one hand, the institutional structures and networks support specific fictions. Some entrepreneurial ideas depend on the institutional framework. Even more, the institutional environment can influence the way these new ideas take root. On the other hand, cognitive frames, shape the direction of imaginaries such as cultural expectations of economic accomplishment. Innovations anchored in modern capitalist societies encourage different imaginaries and associated actions. It must be understood that economic institutions do not emerge in response to economic needs (Granovetter, 1992). These institutions are constructed by the actions of individuals that facilitate and constrain the availability of resources and the structure of the social networks in which they are embedded. Economic institutions are built based on activity patterns in personal networks as it is the case with the development of business groups or firms during the evolution of an industry (Granovetter, 1992).
The attempts to combine social field and innovation frameworks theories is relatively new. There are not so many researches that explain technological innovation through the interplay of the three social forces: institutions, networks and cognitive frames. The first attempts can be seen in the articles written by Roncevic and Modic (2011a, b; Modic and Roncevic (2018) or Cepoi and Golob (2016; 2017) which explore innovation systems through the frame of social fields. According to them in the recent intellectual development the focus is on the complexity of the social life through globalization and technological development. The second development refers to the shift towards multi-level responsibilities of social and economic policies. Roncevic and Modic were able to empirically verify the influence of the social forces on social fields of technological innovations (Roncevic and Modic, 2011a, b).

Therefore, the study addresses the innovation system from a regional prespective, the units of the analysis represent different regions. Following this line of argument, regional innovation systems are seen as particular social fields which are embedded in a broader environment. Furthermore, the field is a local order or a social arena where the actors interact. This aspect goes along with sociological economy where economic processes are explained with the help of social structures on individual actions.

Innovations: In the era of open innovation, the role of SMEs must increase and innovation interaction or cooperation are already part of the culture of SMEs who wish to promote their innovation capabilities in developing countries and emerging economies (Zeng et al., 2010). Chesbrough (2006) defines open innovation as: "the use of purposive inflows and outflows of knowledge to accelerate internal innovation and expand the markets for external use of innovation". Initially, it was understood as a collaboration between two enterprises which opened the internal process of innovation. Truthfully, it can be seen as an opposite to the closed innovation model where internally developed products and services remain in the enterprise (Chesbrough, 2012). There are at least three factors which helped the paradigm of open innovation to gain success among scholars. The first factor is the understanding innovative ideas as coming from the outside of the enterprise. Secondly, the framework of the open innovation builds on the idea of emphasizing the importance of challenges that firms face capturing returns from their innovative effort. Thirdly, at forefront was the study where the results pointed that the role of the business model was to mediate between the technical inputs and economic benefits of a technology by structuring how a firm created and captured value from a specific market (West et al., 2014). Nevertheless as 
Chesbrough points, the concept still has room for development. The concept orchestrates the role of different stakeholders in the innovation process (Chesbrough, 2012). As a result innovation communities will be at forefront in the context of open innovation. The relative new field of research offers new opportunities in the enrichment of discoveries, both empirical and theoretical developments in openness and in the understanding of the innovation process (West et al., 2014).

Schott and Jensen (2016) present a two-level perspective of the innovation process which includes the involvement of institutions and networking between firms. Regulations such as contract laws, tax structures, trade laws or property right laws regulate the elements of inter-firm collaborations that make them attractive for other business partners (Schott and Jensen, 2016). The results show that the institutional support for networking has an impact not only on the quantity of networking but also on its intensity. Even more, it is considered that the process and product of innovation are outcomes networking with the support of institutions (Schott and Jensen, 2016). Nevertheless, even if networking has a positive impact on product and process of innovation, there is still some ambiguity regarding the network's composition and characteristics.

In order to measure the level of innovation performance in the regions, stakeholders were asked to discuss and rate the following aspects related to the innovation performance:

- Level of innovation

- Innovation information

- $\quad$ Enterprises and R\&D

- Final product orientation

Institutions: Sociological institutionalism focuses on organizational fields (Beckert, 2010). Institutional change is based on several mechanisms and coercion is one of them (DiMaggio and Powell, 1983). Coercion is exercised either directly or indirectly, by making the access to resources dependent on compliance. Another mechanism is exercised through power that helps institutions to impose regulations. Despite this, the institutional change can also rely on mediation through professional networks or socialization.

According to the OECD. (2010), regional institutions have various roles in innovation processes such as to create opportunities for innovation, help technology diffusion and encourage technology entrepreneurship, formulate innovation policy or conduct basic and applied research. The creation of the appropriate context for knowledge transfer and creation relies on regional innovation policies and regional stakeholders in science and technology (Huggins and Kitagawa, 2012). Also, various institutions have different impact because institutions depend on the domestic economic environment.

The causal direction between institutions and economic development has been an issue of debate among scholars for many decades. Nevertheless, we rather deal with a bi-directional causality between the two. On one hand in higher income countries institutions generate economic development. On the other hand in lower income countries the direction is reversed, as economic development causes institutions (Law et al., 2013).

Drucker (1992) highlighted four main pillars of the knowledge economy. The first pillar refers to the institutional regime which should provide efficient policies, mobilize and allocate resources and stimulate an efficient creation. The second refers to educated and skilled workers. The third pillar refers to the assimilation of knowledge and the capacity to adapt with the help of innovation systems, universities, research centers, etc. The last pillar highlights the importance of information infrastructure to communicate, disseminate and process information and knowledge. At the regional level intellectual capital is seen as asynergy of a system which is compressed of innovations, market presence, community influence organizations, policy makers, knowledge and other. Hence intellectual capital is more than just patents or other forms of intellectual property (Rusu-Tanasa, 2015).Scholars argue that intangible resources and hidden capabilities foster the development of countries, regions or economic sectors. Recently institutions have been connected theoretically and empirically to R\&D and innovation activities as well as their effects on productivity and economic growth (Krammer, 2015). Knowledge-based capital emerges from investments in non-physical assets such as new organizational processes, specific skills and designs of products or services and R\&D (Rusu-Tanasa, 2015).

Following this line of argument, during the focus group in order to understand how the institutional framework influences innovation performance, stakeholders were asked to scale:

- Role of public authorities

- Capacity to attract talented people

- Capacity to retain

- Region innovation policy

Networks: Theories of regional clustering of industries focus on the notion of innovation interactions in regional networks and industrial districts (Markusen, 2003). Because of the development of regional clusters innovation cooperation for SMEs is based on industrial districts and regional networks (Zeng et al., 2010). Cooperation and synergies can be regarded as sources for benefits within the regional innovation systems. 
Furthermore industrial clusters are fostered by indirect and direct linkages of institutions, regional governments, universities and economic actors. As Su and Chen highlight, the institutional infrastructure that supports innovation within a region is perceived as a regional innovation system. As a result, all actors that are involved in the innovation process from the regional setting are embedded in the social-cultural environments of that region. Both public and private agents form networks within which they interact and they give and receive feedback. These networks operate in a specific territory where they generate and adapt knowledge and innovation. These processes determine the existence of the RIS (Yam et al., 2011). Conditions of sustainability are altered by the society and economy and external and internal forces continuously change the environments and sub-systems where the society and economy are part of it (Gaziulusoy and Brezet, 2015).

It must be considered that innovation outcomes are born from the cooperation of actors. These actors operate in a setting where learning and the exchange of resources and knowledge is necessary. Therefore, long-term alliances are vital for the innovation process (Jakobsen and Aarset, 2010). Technological innovation happens in collaborative arrangements or in other words networks while cooperation is a primordial aspect of economic activities (Beckert, 1999). Each actor involved in economic activities has a different knowledge of their capabilities, quality of products and intentions. In addition, the ability to persuade other actors to cooperate is a strategic social skill and a prerequisite for the emergence of stable social fields.

It is considered that not always social networks can thrive in spite of their non-economic reasons. Nevertheless as Granoveter (2005) stresses any type of social interaction transmits information and details information regarding job flows. The processes within innovation networks are constantly changing and have strong cognitive and social aspects which makes them difficult to characterize. As a result, during the whole process, participants from different areas control those cognitive and social aspects. It must be understood that the social structure affects many economic outcomes including the choice of alliance partners. Moreover, according to Granovetter (2005), the social structure affects the diffusion of governance techniques, persistence of family and ethnically oriented business groups in advanced economies and decisions to acquire other firms and strategies. Thus, the network framework was measured with the help of:

- Network organization

- Cooperation in the region

- Cooperation outside the region

- Level of trust
Cognitive frames: The embedded characteristic of cultural values but also of their property of slower change in comparison to economic policies (Uhlaner and Thurik, 2010), make these important for the explanation of cognitive frames. The social, economic and political differences in the period of transition can be explained by historical and cultural background (Adam et al., 2005). During economic crises, new ideas and ways of economic reconstructions are emerging (Efrat, 2014). For that reason innovation is at the core of the knowledge economy in the information age. Creativity and value creation processes are at the heart of business and they are increasingly important. Even if aspects such as investments in infrastructure, machinery or human capital are important, the ideas of how and where to use them are the background of business growth and development (Andersson et al., 2016). The sources of knowledge and their outlets to innovation expansion are rooted in the globalization context while selling the new outputs. The literature highlights that both globalization and national culture exert influence on $R \& D$ performance. If a company wants to innovate, it must consider national aspects of a milieu that is favourable to innovation (Jones and Davis, 2000). Even if the amount of resources spent for innovations are high, undermining the national culture could lead the rejection of innovations. Nevertheless, there is no common and precise definition of culture which makes it difficult to examine it in relation to innovation (McGrath and MacMillan, 1992).

One of the culture's role is to diffuse, activate and select among available schemata when it is helped by institutions, networks and social movements (DiMaggio, 1997). It is primordial to understand and to develop the idea of culture as an interaction of shared cognitive structure and supra-individual cultural phenomena. The phenomena comprise aspects as media messages, conversations or material culture that activate the cognitive structure and supra-individual cultural structures (DiMaggio, 1997).

The intensity of business creation depends on the values of a society (Bruton et al., 2010). That is why some societies are more inclined to entrepreneurial activity and innovation than others (Turro et al., 2014). As a result, cultural differences impact entrepreneurial activity. Behaviors and values embedded in a firm's culture help the innovation process (Mumford et al., 2002) as the role of values is to provide a mechanism through which the senior management exerts its influence. Therefore, language and stories, physical configurations and organizational rituals lead to innovation development within firms. In an organization, values are understood as standards for the working environment which guide employees on what is "right" and "wrong". Moreover, these values guide specific norms of behavior 
(Dose, 1997). In the moment, the society's norms deviate from what is represented as normal, it is acknowledged that the culture is inconsistent. Therefore, at this stage it is at upmost importance to identify the units of cultural analysis and to focus attention upon the relations among them (DiMaggio, 1997). Even more, culture stops being a latent variable and becomes analogous to that of education income and place of residence to social stratification.

Cognitive structures, can constrain and enable and they create tension within the organizational institutionalism. In the case of constrain, it is iterated that the possibilities for action depend on how stakeholders see and interpret the world because certain possibilities are not recognized due to the cognitive biases of actors. Nevertheless by providing cues and scripts which are legitimate forms of action, cognitive structures can come up with solutions for their problems (Campbell, 1998). The process of bricolage is one way to craft solutions to these problems. Additionally, these structures recombine available and legitimate models, scripts, concepts and cultural artefacts which are embedded in their institutional environment. The result changes as old institutional elements modify and recombine in new socially acceptable ways. Moreover as the researchers highlights, actors construct their world views and devise strategies of action with the help of culture which is a tool for these purposes (Campbell, 1998). Lastly in order to measure the last social force, cognitive frames, stakeholders had to rate:

- Creativity and entrepreneurship

- Attitudes toward learning processes

- Competition

- Globalization

\section{MATERIALS AND METHODS}

The social field theory explains the importance of the meso-level orders asthe aggregation of economy, state or civil society organisation; proximate and distal fields; and following the process of meaning interest and identity. Form the methodological perspective, Fligstein and McAdam (2012), point that the framework presented by them, poses four main challenges:

- To define and verify the existence of a field

- To differentiate between different strategic action fields (emergent, stable and transforming)

- To assess the critical relationship between any given field and external actors

- To account for the role of social skill and entrepreneurial action in a field
In order to address the aspects presented by Fligstein and McAdam, we conducted focus groups with regional stakeholders (representatives from regional institutions, higher education institutions and small and medium enterprises) in seven regions from different countries:

- Slovenia-Eastern region

- Serbia-Sumadija and Western Serbia region

- Romania-North-West region

- Republic of Moldova-North region

- Ireland-South-East region

- Italy-Friuli-Venezia Giulia region

- United Kingdom-North-West region

These regions have different levels of innovation performance. Thus with the obtained information from the focus groups we were able to proceed with fuzzy set analysis. We used this method because in a comparative case study, the number of observations is too low in order to apply any other statistical method. Moreover, this approach allows to frame the causal complexity (Schneider, 2009) and is suited for small-N comparative study in which number of cases are limited or the researcher deliberately chooses a limited number of cases. Within this fuzzy-set analysis we are allowed to determine necessary and sufficient the presence or absence of conditions (or combination of conditions) for any particular outcome (Ragin, 2006). QCA has the property of combining conditions that produce the outcome (the researched phenomenon). Therefore, different combinations can produce the same outcome, even though the context can influence the impact on the outcome (Rihoux, 2003). Nevertheless, besides providing information about the necessary and sufficient conditions for Innovation (as an outcome), the analysis allows to test the validity of the results obtained from the interviews. In order to do so, it is important to consider two parameters of fit: consistency and coverage. These provide numerical expressions for how well the QCA solution term represents the underlying data from which it has been generated (Schneider and Wagemann, 2007 cited in Schneider, 2009). On one hand as Ragin (2008) points consistency indicates how closely a perfect subset relation is approximated, meanwhile on the other hand coverage assesses the degree to which a cause or causal combination "accounts for" instances of an outcome. Thus, it can be stressed that it measures the empirical relevance or importance.

\section{RESULTS AND DISCUSSION}

Conditions explaining innovation: As mentioned in the previous chapter, QCA allows to determine necessary and sufficient conditions for a certain outcome. In the 
The Soc. Sci., 14 (12): 423-430, 2019

Table 1: Presence of Sufficient conditions for innovation

\begin{tabular}{lcc}
\hline Conditions & Cons. suf & Cov. suf \\
\hline Institutions & 0.753 & 0.729 \\
Cognitive frames & 0.695 & 0.900 \\
Networks & 0.577 & 0.689 \\
\hline
\end{tabular}

Table 2: Presence of necessary conditi ons for innovations

\begin{tabular}{lcc}
\hline Conditions & Cons. nec & Cov. nec \\
\hline Institutions & 0.729 & 0.753 \\
Cognitive frames & 0.900 & 0.695 \\
Networks & 0.689 & 0.577 \\
\hline
\end{tabular}

Table 3: Combined necessary and sufficient conditions

\begin{tabular}{llcc}
\hline Conditions & Relation & Consistency & Coverage \\
\hline Institutions+networks & Necessity & 0.857 & 0.602 \\
Cognitive frames* networks & Sufficiency & 0.883 & 0.689 \\
\hline
\end{tabular}

Cognitive frames* networks Sufficiency 0.883

Author's own calculations

proposed model innovation was set as the outcome, meanwhile institutions, networks and cognitive frames as conditions. Additionally, to consider a condition as necessary or sufficient, we set the threshold of 0.75 for consistency. Following this line of argument, the analysis has highlighted the following sufficient conditions for innovation to happen in the selected cases (Table 1).

On one hand as sufficient conditions, the results highlighted institutions as being at forefront, meanwhile cognitive frames are at the threshold. On the other hand, cognitive frames are considered as a necessary condition for innovation to happen. Nevertheless, the institutions condition is at the threshold (Table 2).

Additionally, we focused on the aggregated set (institutions, cognitive frames, networks) but also on each set that constituted these social forces. When it comes to the social forces, the analysis has highlighted the importance of networks for both necessary and sufficient conditions (Table 3).

The results show that in the more complex analysis, for the selected case studies on one hand it is necessary to a combination between two social forces: institutions and networks. On the other hand, it is sufficient to have the presence of cognitive frames and networks for innovation. Following this line of augment, the statement is backed by the scores for consistency and coverage.

However is this the entire picture that the tool allows to see? In order to answer this question, we performed an additional analysis (truth tables) in QCA, to get more details of how do social forces shape the social fields of innovation. The origin of the truth table is in the formal logic. The difference from a simple standard matrix relies in the meaning of each row. If in a standard matrix a new row would denote a new case in the truth table it denotes one of the possible combinations of conditions. Additionally, the truth table's central role is to analyse the set-theoretic sufficiency relation. Following this line of argument, to get more information, we analyzed the data by performing a truth table for all three social forces (Table 4):
Table 4: Truth table for all three social forces

\begin{tabular}{|c|c|c|c|c|c|c|c|}
\hline Institutions & $\begin{array}{c}\text { Cognitive } \\
\text { frames }\end{array}$ & Networks & Out & $\mathrm{n}$ & Incl. & PRI & Cases \\
\hline 1 & 1 & 1 & 1 & 1 & 0.898 & 0.816 & Waterford \\
\hline 0 & 1 & 1 & 1 & 1 & 0.816 & 0.000 & Novo Mesto \\
\hline 0 & 0 & 1 & 0 & 1 & 0.354 & 0.000 & Carlisle \\
\hline 0 & 0 & 0 & 0 & 4 & 0.280 & 0.000 & $\begin{array}{l}\text { Cluj, } \\
\text { Kragujevac, } \\
\text { Balti, Trieste }\end{array}$ \\
\hline
\end{tabular}

Author's own calculations

Thus, the truth table shows that in the case of Waterford (Ireland) we have the presence of all three conditions. In the case of Novo Mesto (Slovenia) there are cognitive frames and networks. In Carlisle (UK) and Cluj (Romania) there are present only networks/nonetheless in Kragujevac (Serbia), Balti (Moldova) and Trieste (Italy) the conditions for innovation processes are absent.

\section{CONCLUSION}

The social and economic complexity of the modern world emphasizes the need of constant improvements for regions to remain competitive and innovative. As such, considering the social field theory, the emphasis is on the three social forces-institutions, networks and cognitive frames in a comparative study of 7 regions. In previous researches, researchers addressed innovation by focusing on a particular aspect. In the case of this study, we managed to demonstrate that it is important to look at innovation processes, regardless of the level of development through the framework of social forces (institutions, networks and cognitive frames). Firstly, the model showed that the presence of the institutional social force is sufficient to have innovation in a given region. Thus, one can argue that state institutions have regulatory power which can improve the milieu for innovation. Additionally, it is at upmost importance that regional authorities create favourable conditions to attract and retain talented people, who will be able to foster innovation. Nevertheless, a special emphasis should also be on the regional innovation policy or at least regional innovation initiatives. At the same, regions need a certain cognitive level of development. As the results show, cognitive frames are considered a necessary condition for innovation. Consequently, the regional population should be creative and entrepreneurial, be prone toward learning new things and see both competition and globalization as positive processes.

Thus, the presented model emphasized that for the case studies, it is necessary to have the presence of institutional and networks social forces for innovation to happen. Nevertheless, the fuzzy-set analysis has pointed that in the moment we have a combination between cognitive frames and networks, it is sufficient for these social forces to boost innovation processes in the selected regions. 
The results presented at the regional level are in accordance with the results obtained in other studies at the national level (Roncevic and Modic 2011a, b; Cepoi and Golob, 2016, 2017). Therefore, it is important to see that the same logic is applied in the context of regional innovation systems as in the case of national innovation systems. The obtained results do not contradict but emphasize the robustness of the model. It is important to point that even current tendencies to focus on decentralization regions are regarded as independent social-political frameworks, though the role of national innovation system remains important. Nonetheless, the model considers the particularities of the specific social fields (either national or regional) and supports the sufficient and necessary factors in the complex context specifics. All in all, we consider that the results present valuable assets for policy-makers, both at regional and national levels who consider in planning innovation systems.

\section{REFERENCES}

Adam, F., M. Makarovic, B. Roncevic and M. Tomsic, 2005. The Challenges of Sustained Development: The Role of Socio-Cultural Factors in East-Central Europe. Central European University Press, Budapest, Hungary, ISBN:9789637326004, Pages: 235.

Andersson, U., A. Dasi, R. Mudambi and T. Pedersen, 2016. Technology, innovation and knowledge: The importance of ideas and international connectivity. J. World Bus., 51: 153-162.

Beckert, J., 1999. Agency, entrepreneurs and institutional change: The role of strategic choice and institutionalized practices in organizations. Organ. Stud., 20: 777-799.

Beckert, J., 2010. How do fields change? The interrelations of institutions, networks and cognition in the dynamics of markets. Organ. Stud., 31: 605-627.

Bruton, G.D., D. Ahlstrom and H.L. Li, 2010. Institutional theory and entrepreneurship: Where are we now and where do we need to move in the future?. Entrepreneurship Theory Pract., 34: 421-440.

Campbell, J.L., 1998. Institutional analysis and the role of ideas in political economy. Theory Soc., 27: 377-409.

Cepoi, V. and T. Golob, 2016. Regional innovation performance: Measuring development in cultural, social and economic perspectives. Peer-Reviewed Acad. J. Innovative Issues Approaches Social Sci., 9: 242-260.

Cepoi, V. and T. Golob, 2017. Innovation performance in the EU comparative perspective: The interplay of social forces in the context of national innovation systems. Comp. Sociology, 16: 555-579.
Chesbrough, H., 2006. Open Innovation: A New Paradigm for Understanding Industrial Innovation. In: Open Innovation: Researching a New Paradigm, Chesbrough, H., W. Vanhaverbeke and J. Wst (Eds.)., Oxford University Press, Oxford, UK., pp: 1-14.

Chesbrough, H., 2012. Open innovation: Where we've been and where we're going. Res. Technol. Manage., 55: 20-27.

Cooke, P., 1992. Regional innovation systems: Competitive regulation in the new Europe. Geoforum, 23: 365-382.

DiMaggio, P., 1997. Culture and cognition. Ann. Rev. Sociology, 23: 263-287.

DiMaggio, P.J. and W.W. Powell, 1983. The iron cage revisited: Institutional isomorphism and collective rationality in organizational fields. Am. Sociol. Rev., 48: 147-160.

Dodescu, A. and L.F. Chirila, 2014. Business environment development and regional policy in North-West region of Romania. Procedia Econ. Finance, 15: 626-634.

Dose, J.J., 1997. Work values: An integrative framework and illustrative application to organizational socialization. J. Occup. Organiz. Psychol., 70: 219-240.

Drucker, P.F., 1992. The new society of organizations. Harvard Bus. Rev., 70: 95-104.

Efrat, K., 2014. The direct and indirect impact of culture on innovation. Technovation, 34: 12-20.

Fligstein, N. and D. McAdam, 2012. A Theory of Fields. Oxford University Press, Oxford, UK., ISBN: 978-0-19-985994-8, Pages: 238.

Gaziulusoy, A.I. and H. Brezet, 2015. Design for system innovations and transitions: A conceptual framework integrating insights from sustainablity science and theories of system innovations and transitions. J. Cleaner Prod., 108: 558-568.

Granovetter, M., 1992. Economic institutions as social constructions: A framework for analysis. Acta Sociologica, 35: 3-11.

Granovetter, M., 2005. The impact of social structure on economic outcomes. J. Econ. Perspect., 19: 33-50.

Huggins, R. and F. Kitagawa, 2012. Regional policy and university knowledge transfer: Perspectives from devolved regions in the UK. Reg. Stud., 46: 817-832.

Jakobsen, S.E. and B. Aarset, 2010. Institutions as facilities for change?: A study of the coherence between political regulations and innovations within the pelagic fisheries sector in Norway. Mar. Policy, 34: 928-934.

Jones, G.K. and H.J. Davis, 2000. National culture and innovation: Implications for locating global R \& D operations. MIR: Manage. Int. Rev., 40: 11-39. 
Kastelle, T., 2009. Generative mechanisms of the world trade web. Proceedings of the Summer Conference 2009 on CBS- Copenhagen Business School Solbjerg Plads 3 DK 2000, June 17-19, 2009, Frederiksberg, Denmark, pp: 2-27.

Kastelle, T., J. Potts and M. Dodgson, 2009. The evolution of innovation systems. Proceedings of the Summer Conference 2009 on CBS-Copenhagen Business School Solbjerg Plads 3 DK 2000, June 17-19, 2009, Frederiksberg, Denmark, pp: 1-26.

Krammer, S.M.S., 2009. Drivers of national innovation in transition: Evidence from a panel of Eastern European countries. Res. Policy, 38: 845-860.

Law, S.H., T.C. Lim and N.W. Ismail, 2013. Institutions and economic development: A granger causality analysis of panel data evidence. Econ. Syst., 37: 610-624.

Markusen, A., 2003. Fuzzy concepts, scanty evidence, policy distance: The case for rigour and policy relevance in critical regional studies. Regional Stud., 37: 701-717.

McGrath, R.G. and I.C. MacMillan, 1992. More like each other than anyone else? A cross-cultural study of entrepreneurial perceptions. J. Bus. Venturing, 7: 419-429.

Modic, D. and B. Roncevic, 2018. Social topography for sustainable innovation policy: Putting institutions, social networks and cognitive frames in their place. Comp. Sociology, 17: 100-127.

Mumford, M.D., G.M. Scott, B. Gaddis and J.M. Strange, 2002. Leading creative people: Orchestrating expertise and relationships. Leadersh. Q., 13: 705-750.

OECD., 2010. The OECD Innovation Strategy Getting a Head Start on Tomorrow: Getting a Head Start on Tomorrow. OECD, Paris, ISBN-13: 9789264083479 , Pages: 224.

Ragin, C.C., 2006. Set relations in social research: Evaluating their consistency and coverage. Political Anal., 14: 291-310.

Ragin, C.C., 2008. Measurement Versus Calibration: A Set-Theoretic Approach. In: The Oxford Handbook of Political Methodology, Box-Steffensmeier, J.M., H.E. Brady and D. Collier (Eds.). Oxford University Press, Oxford, UK., ISBN: 9780199286546, pp: 174-198.
Rihoux, B., 2003. Bridging the gap between the qualitative and quantitative worlds? A retrospective and prospective view on qualitative comparative analysis. Field Methods, 15: 351-365.

Robins, J.M., 1999. Association, causation and marginal structural models. Synthese, 121: 151-179.

Roncevic, B. and D. Modic, 2011b. Regional systems of innovations as social fields. Sociologija Prostor Casopis Istrazivanje Prostornoga Sociokulturnog Razvoja, 49: 313-333.

Roncevic, B. and D. Modic, 2011a. Social Fields of Technological Innovations. In: Global Trends and Regional Development, Genov, N. (Ed.). Routledge, London, England, UK., ISBN:9781136633478, pp: 226-240.

Rusu-Tanasa, M., 2015. Intellectual capital a strategic factor of socio-economic development of regions and countries. Procedia Econ. Finance, 27: 369-374.

Schneider, C.Q., 2009. The Consolidation of Democracy: Comparing Europe and Latin America. Routledge, Abingdon, UK., ISBN: 9780415468060, Pages: 208.

Schott, T. and K.W. Jensen, 2016. Firms innovation benefiting from networking and institutional support: A global analysis of national and firm effects. Res. Policy, 45: 1233-1246.

Turro, A., D. Urbano and M. Peris-Ortiz, 2014. Culture and innovation: The moderating effect of cultural values on corporate entrepreneurship. Technol. Forecasting Social Change, 88: 360-369.

Uhlaner, L. and R. Thurik, 2010. Postmaterialism influencing total entrepreneurial activity across nations. J. Evol. Econ., 17: 161-185.

West, J., A. Salter, W. Vanhaverbeke and H. Chesbrough, 2014. Open innovation: The next decade. Res. Policy, 43: 805-811.

Wilkinson, K.P., 1970. Phases and roles in community action. Rural Sociology, 35: 54-68.

Yam, R.C.M., W. Lo, E.P.Y. Tang and A.K.W. Lau, 2011. Analysis of sources of innovation, technological innovation capabilities and performance: An empirical study of Hong Kong manufacturing industries. Res. Policy, 40: 391-402.

Zeng, Y., Y.C. Liang, A.T. Hoang and R. Zhang, 2010. A review on spectrum sensing for cognitive radio: Challenges and solutions. EURASIP J. Adv. Signal Process., Vol. 2010. 10.1155/2010/381465 